\title{
DEVELOPMENT AND IN VITRO PENETRATION TEST OF ETHOSOMAL CREAM-CONTAINING PEGAGAN (CENTELLA ASIATICA) HERBAL EXTRACT
}

\author{
ARINI DYAH SRI PUSPITA DEWI, MAHDI JUFRI, ISKANDARSYAH* \\ Laboratory of Physical Pharmacy, Faculty of Pharmacy, Universitas Indonesia, Depok, 16424, Indonesia. Email: aya_2803@yahoo.com \\ Received: 18 April 2018, Revised and Accepted: 28 September 2018 and 05 November 2018
}

ABSTRACT

Objective: This study aimed to formulate and characterize ethosome-containing Centella asiatica herbal extract at various concentrations and evaluate the in vitro penetration ability of an ethosome-containing cream.

Methods: The ethosomes were formulated using a thin-layer hydration method with a rotary vacuum evaporator. The asiaticoside content was determined by thin-layer chromatography densitometry.

Results: Based on the characterization results, F1 was the best ethosomal formula. F1 had the properties of a spherical shape, entrapment efficiency of $75.03 \pm 0.295 \%$, particle size of $94.71 \pm 2.807 \mathrm{~nm}$, and zeta potential of $-25.067 \pm 0.814 \mathrm{mV}$. Therefore, the F1 ethosomes were formulated into a cream with a stearic acid base. The physical stability and in vitro penetration ability of the ethosomal cream were evaluated using Franz diffusion cells and then compared to a non-ethosomal cream. Based on the results of the penetration study, the cumulative penetration and flux rates of the ethosomal cream were superior to those of the non-ethosomal cream. The cumulative penetration depths of the ethosomal and non-ethosomal creams were $3651.271 \pm 37.579$ and $2873.016 \pm 36.850 \mu \mathrm{g} / \mathrm{cm}^{2}$, respectively.

Conclusion: Incorporation of asiaticoside into ethosomes can increase its skin penetration ability.

Keywords: Asiaticoside, Centella asiatica, Cream, Ethosomes, Franz diffusion cell, Penetration.

(c) 2018 The Authors. Published by Innovare Academic Sciences Pvt Ltd. This is an open access article under the CC BY license (http://creativecommons. org/licenses/by/4. 0/) DOI: http://dx.doi.org/10.22159/ijap.2018.v10s1.25

\section{INTRODUCTION}

The prevalence of stretch marks in the general human population is $50 \%-90 \%$ and is mostly found in pregnant women and obese patients. Comparison of skin biopsy results between skin with stretch marks and normal skin showed structural changes and a decreased amount of elastic fibers in the former. Although not clinically significant, stretch marks become a concern owing to reduced esthetics and psychological disruption. To date, stretch marks remain an elusive problem with no standardized treatment [1].

Centella asiatica (Pegagan) is an herbaceous, frost-sensitive perennial plant that grows abundantly in Indonesia and contains many biologically active compounds [2]. One of the compounds, asiaticoside, is commonly used for wound healing and inhibits the proliferative activity of keloids and hypertrophic scars [3]. The suggested mechanism of the prevention of stretch marks is wound healing through the stimulation of fibroblasts to synthesize collagen, which plays a role in the formation of new skin tissues and inhibits the effects of glucocorticoids $[4,5]$. However, asiaticoside has poor water solubility and oil-water partition coefficients, which limit its use in pharmaceutical dosage forms [6].

Ethosomes have been shown to modify the liposome bilayer and are thus suitable as carriers for the delivery of topical and transdermal drugs. Ethosomes have high elasticity and can pass through a small gap with good entrapment efficiency that enables penetration of the deeper layers of the skin, thus facilitating drug delivery through the skin $[7,8]$.

To improve the effectiveness of stretch mark therapy, asiaticoside must be absorbed into the dermis to interact with fibroblasts. Therefore, in the present study, the extract was formulated in ethosomes. Asiaticoside is suitable to be formulated in ethosomes because it is quite soluble in ethanol. In this study, ethosomes containing herbal extracts at concentrations of $0.6 \%, 1 \%$, and $1.4 \% \mathrm{w} / \mathrm{v}$ were formulated and characterized. Then, the ethosomal formulation with the best characterization was selected for incorporation in cream. The in vitro penetration of ethosomal and non-ethosomal creams containing C. asiatica extract was evaluated using Franz diffusion cells.

\section{MATERIALS AND METHODS}

\section{Instruments}

The instruments used in this study included a rotary vacuum evaporator (Hahnshin Scientific Co., Bucheon, South Korea), analytical scale (Sartorius AG, Göttingen, Germany), refrigerator (Panasonic Corporation, Osaka, Japan), homogenizer (Omni-Multimix Inc., Malaysia), vortex mixer VM-200 (Digisystem Laboratory Instruments, Inc., New Taipei City, Taiwan), sonicator (Sonica, Nanotechnology Laboratory Agricultural Postharvest Office, Indonesia), pH meter 510 (Eutech Instrument, Singapore), Brookfield viscometer (AMETEK Brookfield, Middleboro, MA, USA), centrifuge, filtered centrifuge tube (Sartorius AG), oven (Memmert GmbH + Co. KG, Schwabach, Germany), conical penetrometer, transmission electron microscope (TEM), dynamic light scattering Zetasizer particle size analyzer (Malvern Panalytical, Malvern, UK), scanner for thin-layer chromatography (TLC) (Camag, Muttenz, Switzerland), silica gel 60 GF254 (Merck KGaA, Darmstadt, Germany), capillary tube ( $2 \mu \mathrm{L}$; Camag), Franz diffusion cells (Bengkel Gelas, Bandung, Indonesia), and various glassware.

\section{Materials}

C. asiatica herbal extracts (Balitro Bogor, Indonesia), soybean phosphatidylcholine (Phospholipon/Phospholipid 90G, Lipoid $\mathrm{GmbH}$, Ludwigshafen am Rhein, Germany), 96\% ethanol (Smart Lab, South Tangerang, Indonesia), propylene glycol (Merck KGaA), dichloromethane (Merck KGaA), distilled water (Brataco Chemik, Jakarta, Indonesia), stearic acid (Brataco Chemik), paraffin liquid (Brataco Chemik), triethanolamine (Brataco Chemik), anhydrous lanolin (Brataco Chemik), methylparaben (Brataco Chemik), 
propylparaben (Brataco Chemik), asiaticoside reference standard (Baoji Guokang Bio-Technology Co. Ltd., Baoji, China), methanol (Merck KGaA), chloroform (Merck KGaA), acetic anhydride (Merck $\mathrm{KGaA}$ ), sulfuric acid (Merck KGaA), and female Sprague Dawley rats (age, 2-3 months; weight, 200 g; Bogor Agricultural Institute, Bogor, Indonesia) were used.

\section{Preparation of $C$. asiatica herbal extract}

C. asiatica was ground into powder, and $1 \mathrm{~kg}$ was extracted by maceration with $70 \%$ ethanol for $24 \mathrm{~h}$. The extraction process was performed at the Herbal and Medicinal Plant Research Office (Bogor, Indonesia). The extraction process yielded $41.215 \pm 0.471 \%$ asiaticoside.

Determination of asiaticoside content in $C$. asiatica herbal extract The asiaticoside content in $C$. asiatica herbal extract was determined by TLC-densitometry. Briefly, a calibration curve was prepared by measuring the concentration of an asiaticoside standard in $70 \%$ ethanol at $1000,800,600,500,400,300$, and 200 ppm. For TLC-densitometry, the stationary phase was silica gel $60 \mathrm{GF} 254$ and the mobile phase was chloroform: Methanol: Water at a ratio of 58:38:4. After the elution process, the plates were sprayed with Liebermann-Burchard reagent and the absorbance was measured at a wavelength of $575 \mathrm{~nm}$.

Formulation of ethosomes using the thin-layer hydration method Appropriate amounts of phospholipid 90G and cholesterol were dissolved in $10 \mathrm{~mL}$ of dichloromethane. Then, the lipid mixture was evaporated in a rotary vacuum evaporator at $30^{\circ} \mathrm{C}$ and $150 \mathrm{rpm}$ for 1-2 $\mathrm{h}$ until a thin layer of lipid was formed in the wall of the roundbottom flask. Nitrogen gas was passed through the thin layer to remove oxygen for preventing oxidation, and the thin layer was kept overnight at $4^{\circ} \mathrm{C}$.

In a separate step, a solvent mixture containing ethanol and propylene glycol at a 4:1 ratio was prepared and added to phosphate buffer $\mathrm{pH} 7.4$ to a final volume of $25 \mathrm{~mL}$. Different amounts of $C$. asiatica extract were then dissolved in the solvent mixture to determine the optimum composition. These mixtures of extract solvents were then used to immerse the lipid thin layer in the rotary vacuum evaporator operating at $100 \mathrm{rpm}$ until a green, light-brownish suspension was observed. The resulting ethosome suspension was homogenized using a vortex mixer and stored in a vial at $4^{\circ} \mathrm{C}$ until use. Ultrasonication was performed to reduce and homogenize the particle size of the ethosomes. The different resulting suspensions were evaluated for the optimal composition based on entrapment efficiency, particle size, and zeta potential. Entrapment efficiency was determined using the indirect method. The ethosome suspension was first separated by centrifugation in a centrifuge flask containing a 5000-Da filter at $5000 \mathrm{rpm}$ for $45 \mathrm{~min}$. The drug content in the supernatant was determined by TLC-densitometry. The drug content contained in the suspension before centrifugation was also determined. Entrapment efficiency was calculated by the difference of Ct and Cs, divided by Ct multiplied by $100 \%$, which $\mathrm{Ct}=$ total asiaticoside concentration in the ethosomes $(\mu \mathrm{g} / \mathrm{mL})$ and $\mathrm{Cs}=$ asiaticoside concentration in the supernatant $(\mu \mathrm{g} / \mathrm{mL})$.

Particle size and zeta potential were measured using dynamic light scattering in which three drops of the suspension were added to $10 \mathrm{~mL}$ of distilled water. The measurements were repeated 3 times using a Zetasizer particle size analyzer. The ethosome suspension was aliquoted onto a carbon-coated copper grid and dried at room temperature before morphological evaluation. Based on the predetermined criteria [9], the suspension with the optimal composition was chosen for the subsequent steps.

Formulation of ethosomal cream containing $C$. asiatica herbal extract

In the subsequent processes, cream was prepared as a vehicle for the ethosomes and crude extract. First, an oil phase comprising stearic acid, paraffin liquid, and anhydrous lanolin at a ratio of 10:30:2 was heated in a water bath at $70^{\circ} \mathrm{C}$. In a separate process, the aqueous phase was prepared by dissolving methylparaben, propylparaben, and triethanolamine in distilled water in a beaker at $70^{\circ} \mathrm{C}$. The two phases were equilibrated to $70^{\circ} \mathrm{C}$ and mixed in a homogenizer at $1000 \mathrm{rpm}$ for $10 \mathrm{~min}$. Two different portions of the cream were collected: One was used as a vehicle for the ethosome suspension and the second for the crude extract. The ethosome suspension or the extract solution was then slowly poured into the different portions of cream. The ethosomecontaining cream was homogenized for $10 \mathrm{~min}$ at $150 \mathrm{rpm}$, and the crude extract-containing cream was homogenized at $1000 \mathrm{rpm}$ for $10 \mathrm{~min}$. Table 1 lists the final composition of the ethosome suspension, and Table 2 lists the composition of the cream.

\section{Cream evaluation}

The creams were evaluated for in vitro penetration, organoleptic property, homogeneity, $\mathrm{pH}$, consistency, viscosity, rheology, and physical stability.

The in vitro penetration test was performed using the Franz diffusion cell test [10-12]. The skin from the abdomen of Sprague Dawley female rats (age, 2-3 months, and weight, $200 \mathrm{~g}$ ) was used as the membrane. The surface area of the membrane was $2.0096 \mathrm{~cm}^{2}$. The receptor contained a compartment with a volume of $15 \mathrm{~mL}$ and was filled with a receptor media mixture composed of phosphate buffer ( $\mathrm{pH} 7.4$ ) and $70 \%$ ethanol at a ratio of 1:1. The temperature of the compartment was maintained at $32 \pm 0.6^{\circ} \mathrm{C}$, and the receptor medium was stirred at $250 \mathrm{rpm}$ using a magnetic stirrer.

About $1 \mathrm{~g}$ of the cream was applied onto the membrane. During the experiment, $4.5-\mathrm{mL}$ aliquots were obtained from the receptor compartment at $0.5,1,1.5,2,3,4,6,8,10$, and $12 \mathrm{~h}$ after the beginning of the experiment. The volumes of media removed from the receptor compartment were replenished with equal volumes.

The amounts of asiaticoside in the samples were determined using TLCdensitometry, as this method is faster than high-performance liquid chromatography. Furthermore, the natural agent had to be separated for analysis; thus, TLC-densitometry was chosen because this method can be used to perform separation and quantification in one step. The

Table 1: Formulation of ethosomes containing C. asiatica herbal extract

\begin{tabular}{llll}
\hline \multirow{2}{*}{ Materials } & \multicolumn{3}{l}{ Formulas (\%) } \\
\cline { 2 - 3 } & F1 & F2 & F3 \\
\hline C. asiatica herbal extract & $0.6(\mathrm{w} / \mathrm{v})$ & $1(\mathrm{w} / \mathrm{v})$ & $1.4(\mathrm{w} / \mathrm{v})$ \\
Phospholipon 90G & $1.4(\mathrm{w} / \mathrm{v})$ & $1.4(\mathrm{w} / \mathrm{v})$ & $1.4(\mathrm{w} / \mathrm{v})$ \\
Cholesterol & $0.07(\mathrm{w} / \mathrm{v})$ & $0.07(\mathrm{w} / \mathrm{v})$ & $0.07(\mathrm{w} / \mathrm{v})$ \\
96\% Ethanol & $20(\mathrm{v} / \mathrm{v})$ & $20(\mathrm{v} / \mathrm{v})$ & $20(\mathrm{v} / \mathrm{v})$ \\
Propylene glycol & $5(\mathrm{v} / \mathrm{v})$ & $5(\mathrm{v} / \mathrm{v})$ & $5(\mathrm{v} / \mathrm{v})$ \\
Phosphate buffer $(\mathrm{pH} 7.4)$ & Add 100\% & Add 100\% & Add 100\% \\
\hline
\end{tabular}

C. asiatica: Centella asiatica

Table 2: Formulations of the ethosomal and non-ethosomal creams containing $C$. asiatica herbal extract

\begin{tabular}{lll}
\hline Materials & \multicolumn{2}{l}{ Concentration (\%) (w/w) } \\
\cline { 2 - 3 } & EC & NEC \\
\hline C. asiatica herbal extract solution & - & 2 \\
C. asiatica herbal extract ethosome & 2.7 & - \\
Stearic acid & 10 & 10 \\
Paraffin liquid & 30 & 30 \\
Triethanolamine & 1.5 & 1.5 \\
Lanolin & 2 & 2 \\
Methylparaben & 0.1 & 0.1 \\
Propylparaben & 0.05 & 0.05 \\
Distilled water & ad 100\% & ad 100\% \\
\hline
\end{tabular}

C. asiatica: Centella asiatica 
in vitro penetration test was performed in triplicates. The cumulative amount of asiaticoside penetrating per diffusion area $\left(\mu \mathrm{g} / \mathrm{cm}^{2}\right)$ was calculated using the formula (1) as described in [9].

$Q=\frac{\left[R . V+\sum_{i=1}^{n-1} C . S\right]}{A}$

Where

Q: The cumulative amount of asiaticoside penetrating per diffusion area $\left(\mu \mathrm{g} / \mathrm{cm}^{2}\right)$

R: Concentration of asiaticoside $(\mu \mathrm{g} / \mathrm{mL})$ at sampling time $\mathrm{n}$

V: Volume of Franz diffusion cells

$\sum_{i=n}^{n-1} C$ time of the first sampling until sampling at the $\mathrm{n}^{\text {th }} \mathrm{h}$.

S: Sampling volume $(45 \mathrm{~mL})$

A; Membrane area $\left(2.0096 \mathrm{~cm}^{2}\right)$

Hence, asiaticoside flux was calculated according Fick first law of diffusion as in equation (2):

$J=\frac{M}{S x t}$

Where

$\mathrm{J}:$ Fluxes $\left(\mu \mathrm{g} / \mathrm{cm}^{2} \mathrm{~h}\right)$

M: The amount of asiaticoside that penetrated through the membrane $(\mu \mathrm{g})$

S: Diffusion membrane area $\left(\mathrm{cm}^{2}\right)$

t: Time (h)

In addition, the viscosity and rheology of the creams were evaluated using a Brookfield viscometer, whereas the consistencies were evaluated with a conical penetrometer. The physical stabilities of the ethosome- and non-ethosome-containing creams at temperatures of $4^{\circ} \mathrm{C}, 30^{\circ} \mathrm{C}$ (room temperature), and $40^{\circ} \mathrm{C}$ were also evaluated for 12 weeks.

\section{RESULTS AND DISCUSSION}

\section{Standard curve calibration of asiaticoside}

Standard curve calibration was used to quantify the asiaticoside content in the extracts and ethosomes. A standard curve of asiaticoside in $70 \%$ ethanol was obtained with the equation $y=-240.57+6.75796 \mathrm{x}$ with an $\mathrm{r}$-value of 0.997254 . The points in the calibration curve were well correlated, as the $r$ value was close to 1 . Based on the calculation using the standard curve, the extraction process yielded $41.215 \pm 0.471 \%$ asiaticoside.

\section{Ethosome characterization}

\section{Physical characteristics}

Based on organoleptic observations, the ethosome suspension of C. asiatica herbal extract was green, light brownish in color, odorous, and opaque and formed sediments that could be easily redispersed.

Determination of the entrapment efficiency of asiaticoside in ethosomes

The entrapment efficiency of ethosomes was determined by the indirect method. The drug contents in the supernatant and the whole suspension before centrifugation were determined by TLCdensitometry. Entrapment efficiency was then estimated using formula (1). The average entrapment efficiency of the ethosomes in F1, F2, and F3 was $75.031 \%, 69.465 \%$, and $53.049 \%$, respectively (Table 3).

\section{Particle size and zeta potential characterization}

Particle size and zeta potential measurements were performed using dynamic light scattering, which is the measurement of light fluctuation that is scattered over timescales of particles with Brownian motion [13]. It is important to characterize the particle sizes of the vesicles because particle size affects skin penetration ability. Vesicles with a particle size $<200 \mathrm{~nm}$ can easily penetrate the skin. The particle sizes of the vesicles in samples F1, F2, and F3 were 94.71, 92.08, and $99.64 \mathrm{~nm}$, respectively.

The zeta potential of samples F1, F2, and F3 was $-25.067,-22.5$, and $27.233 \mathrm{mV}$, respectively. These forces were lower than $-30 \mathrm{mV}$, indicating that lower Van der Waal attraction forces caused the vesicles to easily agglomerate. The $7.4 \mathrm{pH}$ phosphate buffer caused greater ionization of the phospholipid 90G, which has an isoelectric point of 6.2 , and influenced the observed zeta potential value.

\section{Morphology characterization}

Further evaluation under a TEM verified that the ethosome vesicles were spherical, with homogenous sizes, and unilamellar with the extract incorporated into the core of vesicle. The vesicles did not agglomerate but were rather separated by short distances. A TEM image of an F1 ethosome is shown in Fig. 1. The characteristics of the ethosomes are summarized in Table 3.

\section{Cream evaluation}

Based on the ethosomal characterization results, the best ethosomal formula was F1. Further evaluation by the cream stability test was conducted at a low temperature $\left(4^{\circ} \mathrm{C}\right)$, room temperature $\left(30^{\circ} \mathrm{C}\right)$, and high temperature $\left(40^{\circ} \mathrm{C}\right)$ over 12 weeks. Both the ethosomal and nonethosomal creams retained their colors, odors, and homogeneities and did not break down when tested at $4^{\circ} \mathrm{C}$ and $30^{\circ} \mathrm{C}$. At $40^{\circ} \mathrm{C}$, both creams also retained their colors, odors, and homogeneities, but after 8 weeks, the ethosomal cream disintegrated. Although the non-ethosomal cream maintained its oily odor and homogeneity at 12 weeks, the color changed after 4 weeks. At week 12, the non-ethosomal cream showed phase separation at a high temperature.

At baseline, the $\mathrm{pH}$ values of the ethosomal and non-ethosomal creams were 8.34 and 8.40, respectively. Although the $\mathrm{pH}$ value decreased at $4^{\circ} \mathrm{C}$ and $30^{\circ} \mathrm{C}$, it was still acceptable.

In addition, after 12 weeks of storage, the particle size of the ethosomal cream had increased significantly, particularly at a storage temperature of $4^{\circ} \mathrm{C}$ and $40^{\circ} \mathrm{C}$, which may have been caused by a reduction in the effectiveness of the surfactant in preventing coalescence. Therefore, it may be concluded that both the ethosomal and non-ethosomal creams were stable for 12 weeks at $4^{\circ} \mathrm{C}, 30^{\circ} \mathrm{C}$, and $40^{\circ} \mathrm{C}$, although the ethosomal cream was more stable than the non-ethosomal cream. After six freezethaw cycles, neither of the creams had crystallized, broken down, or

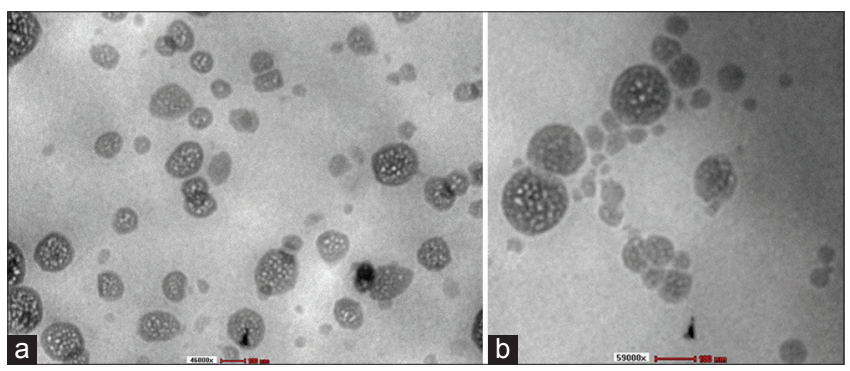

Fig. 1: ( $a$ and b) Morphological characterization of F1 ethosomes using a transmission electron microscope 
Table 3: Ethosome characterization results

\begin{tabular}{llllll}
\hline Formula & $\begin{array}{l}\text { Vesicle } \\
\text { morphology }\end{array}$ & $\begin{array}{l}\text { Particle } \\
\text { size }(\mathbf{n m})\end{array}$ & $\begin{array}{l}\text { Polydispersity } \\
\text { index }\end{array}$ & $\begin{array}{l}\text { Zeta } \\
\text { potential (mV) }\end{array}$ & $\begin{array}{l}\text { Entrapment } \\
\text { efficiency }(\%)\end{array}$ \\
\hline F1 & Spherical & $94.71 \pm 2.807$ & $0.338 \pm 0.046$ & $-25.067 \pm 0.814$ & $75.031 \pm 0.295$ \\
F2 & & $92.08 \pm 2.868$ & $0.376 \pm 0.023$ & $-22.5 \pm 0.7$ & $69.579 \pm 1.049$ \\
F3 & $99.64 \pm 2.395$ & $0.390 \pm 0.009$ & $-27.233 \pm 1.940$ & $49.690 \pm 0.298$ \\
\hline
\end{tabular}

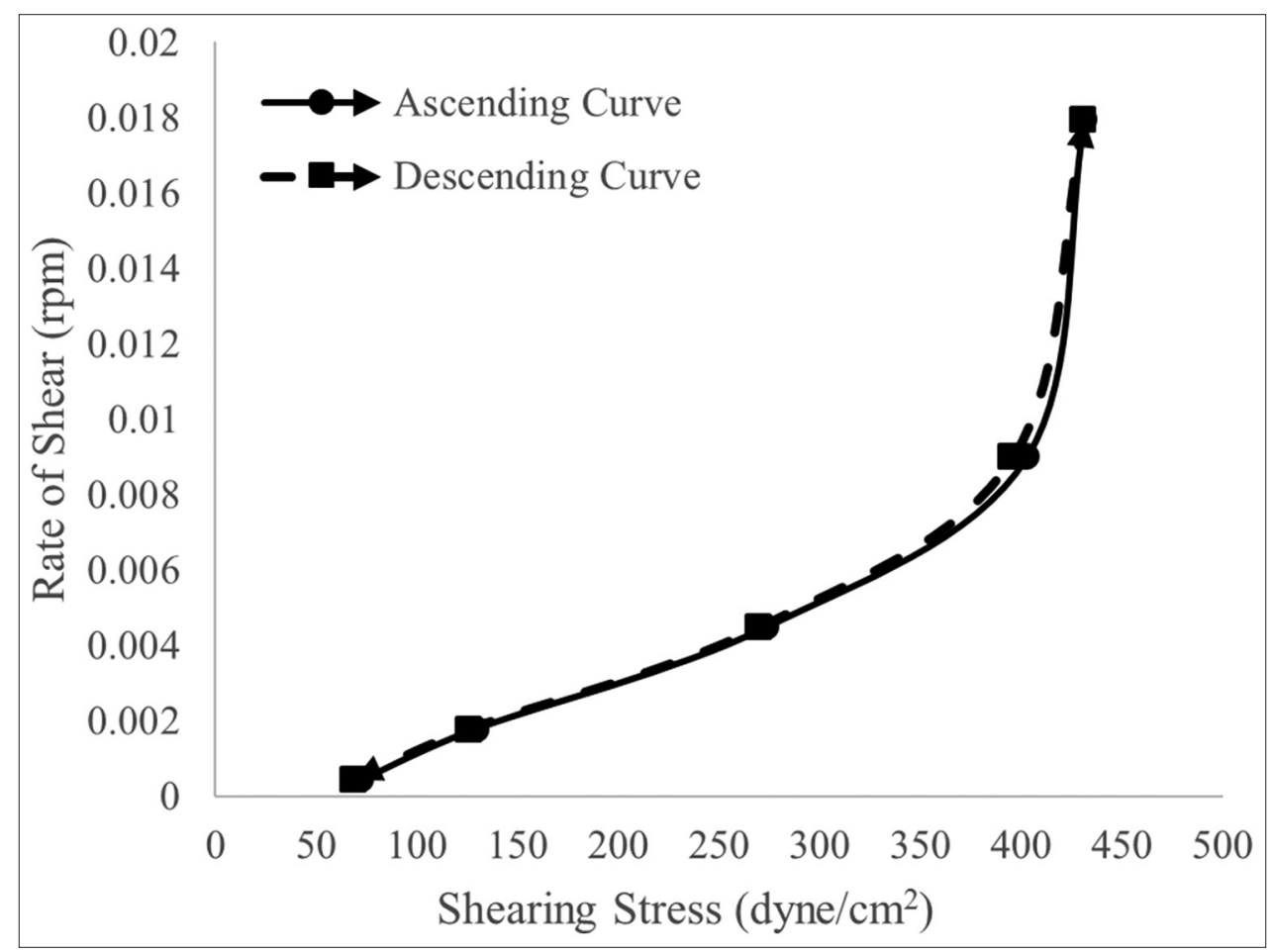

Fig. 2: Rheogram curve of the ethosomal cream

undergone organoleptic change. In addition, there was no evidence of phase separation.

In terms of consistency test results, values of 372 and 353 dynes $/ \mathrm{cm}^{3}$ for the ethosomal and non-ethosomal creams, respectively, indicated that both creams had good consistency.Viscosity and rheologymeasurements showed that the ethosomal cream exhibited pseudoplastic rheology, whereas the non-ethosomal cream had thixotropic pseudoplastic characteristics. Rheograms of both creams are shown in Figs. 2 and 3.

\section{In vitro penetration test}

In vitro penetration test for $12 \mathrm{~h}$ revealed that the cumulative penetrations of the ethosome and non-ethosomal cream were $3809.73 \pm 17.20$ and $2371.788 \pm 50.209 \mu \mathrm{g} / \mathrm{cm}^{2}$, respectively, which corresponded to percentage penetration rates of $67.073 \%$ and $57.570 \%$, respectively. These values complied with the penetration profile requirements of the Food and Drug Administration for active ingredients in the creams.

The penetration profiles of asiaticoside from the creams are shown in Fig. 4. The flux rates of the ethosomal and non-ethosomal creams were $239.38 \pm 3.437$ and $164.33 \pm 3.522 \mu \mathrm{g} / \mathrm{h} \cdot \mathrm{cm}^{-2}$, respectively. The average penetration flux rates of asiaticoside in the ethosomal and nonethosomal cream are shown in Fig. 5.

\section{DISCUSSION}

The ethosome suspension of $C$. asiatica herbal extract had characteristics of a green, light-brownish color, was odorous and opaque, and had formed sediments that could be easily redispersed. However, the ethosomal characteristics were relatively subjective because observations were made with the naked eye. Future studies are required to evaluate the physical characteristics that are readily measurable, such as the melting point, densitometry, and absorbance. The most important characterization parameter of the ethosomes was drug entrapment efficiency, which was calculated using the formula as shown in equation 1 . The amount of drug entrapped in the ethosomes was calculated by the difference between the total amount of drug in the suspension and the amount of non-entrapped drug remaining in the aqueous supernatant [14]. At the same phospholipid 90G concentration, the smaller was the concentration of the extract in the ethosomes, the larger was the entrapment efficiency. This suggested that phospholipid 90G had a maximum capacity to entrap active molecules, which would limit the extract concentration in the ethosome. Nevertheless, it was also possible that the extract was not entrapped because it was degraded in the processes before or during ethosome formation. In our optimization experiments (result not shown), the entrapment efficiency of the ethosomes was also affected by cholesterol concentrations, as cholesterol can increase vesicle rigidity owing to the lipid bilayer condensation effect [15].

There was no significant difference in the particle sizes among the three ethosomes probably because all contained the same concentrations of ethanol and phospholipid [16]. Ultrasonication reduced the particle size (result not shown), and based on the polydispersity index of $<0.5$ in this study, the ethosomes were homogenous. Thus, the particle size and homogeneity satisfied public standards [10]. The zeta potential is an electrostatic force (attraction or repulsion) occurring between adjacent particles. Zeta potential measurement is important to predict the stability of a suspension during storage. An ethosome suspension with a zeta potential value of $<-30 \mathrm{mV}$ or $>+30 \mathrm{mV}$ is stable [13]. These 


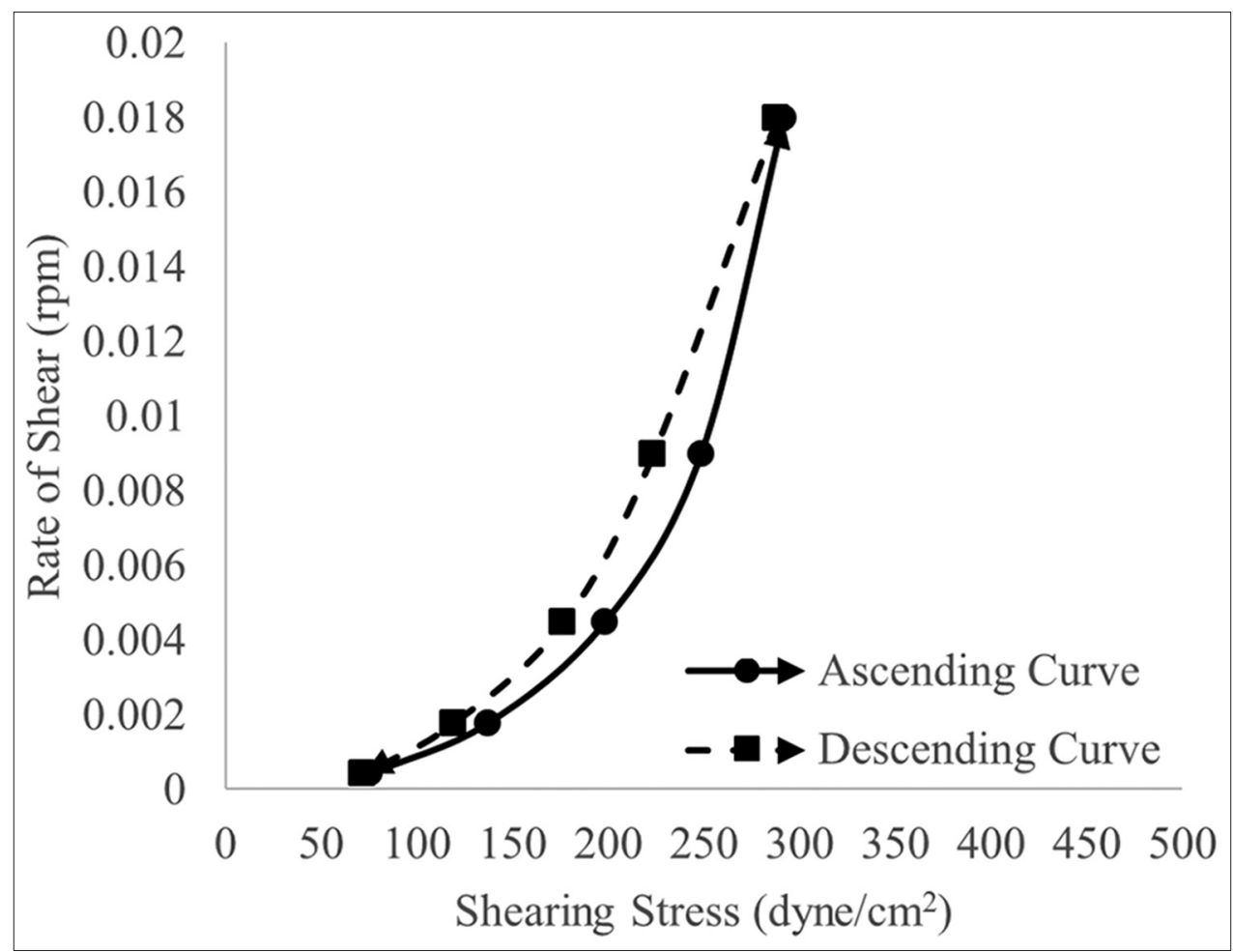

Fig. 3: Rheogram curve of the non-ethosomal cream

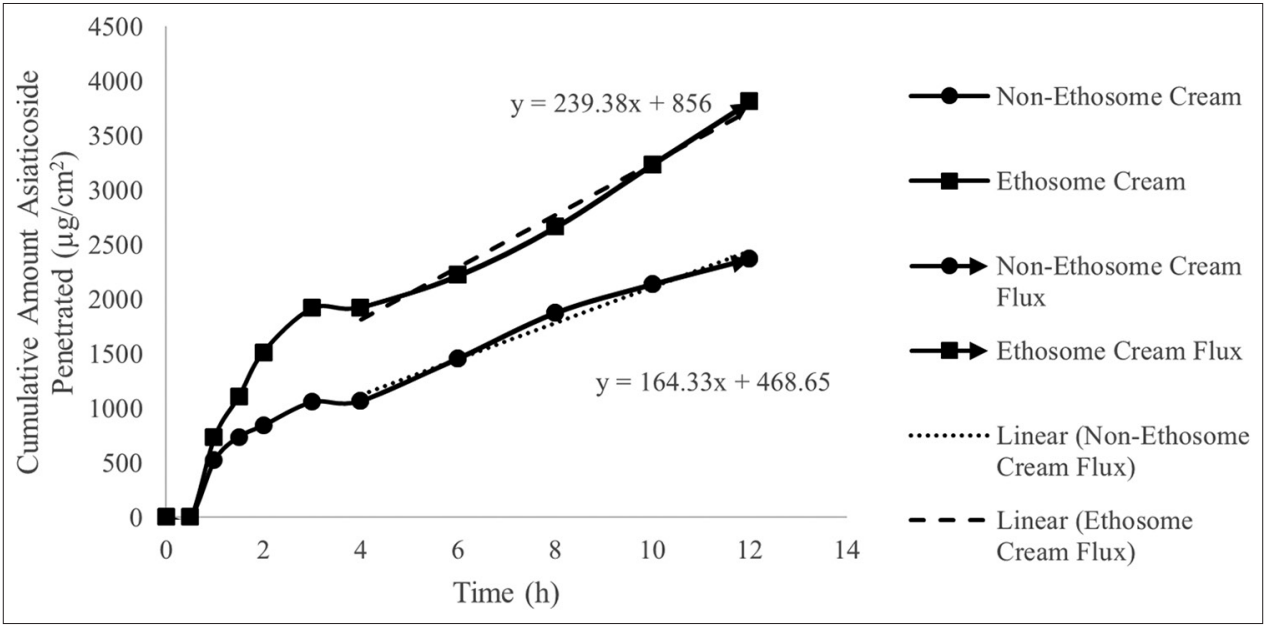

Fig. 4: Penetration profile of asiaticoside in the ethosomal and non-ethosomal creams

forces were $>-30 \mathrm{mV}$, indicating that forces less than Van der Waal attraction forces would cause the vesicle to easily agglomerate. The 7.4 $\mathrm{pH}$ phosphate buffer caused greater ionization of the phospholipid 90G, which has an isoelectric point of 6.2, and also influenced the observed zeta potential value. Based on morphology characterizations, the extract was incorporated into the core of vesicle because a hydrophilic microenvironment facilitates the dissolution of polar extracts in the vesicle. Despite the short distances separating the ethosomes, the high zeta potential prevented coalescence.

Based on cream evaluation, the $\mathrm{pH}$ values of both creams were more basic than skin $\mathrm{pH}$ owing to the triethanolamine and stearic acid contents. During storage, the $\mathrm{pH}$ values of both creams decreased because of oxidation of the extract. Based on viscosity and rheology measurements, the non-ethosomal cream was more viscous than the ethosomal cream, probably due to the higher homogenization speed. Based on flux values, skin penetration was better with the ethosomal cream. The sizes of the ethosomes were smaller, which facilitated penetration into the lipid bilayer and transfered across the stratum corneum. Propylene glycol in the formulation may have also acted as a penetration enhancer. In addition, the phospholipid component of the ethosome is easily soluble in the phospholipid bilayer of the stratum corneum [17]. Despite a molecular size of $959.12 \mathrm{~g} / \mathrm{mole}$, the incorporation of asiaticoside into nanoparticle-sized ethosomes allowed for improved skin penetration ability of the asiaticoside by passive diffusion. Asiaticoside has a hydrophilic coefficient of the partition of 2.24 that improves permeability [6]. The ethosomal cream also has lower viscosity than that of the non-ethosomal cream, which also facilitated penetration. Creams with a low viscosity are more easily absorbed by the skin because diffusion is not impended. The higher concentration of the active ingredients of the ethosomal cream increased the concentration gradient across the skin and facilitated penetration [18]. 


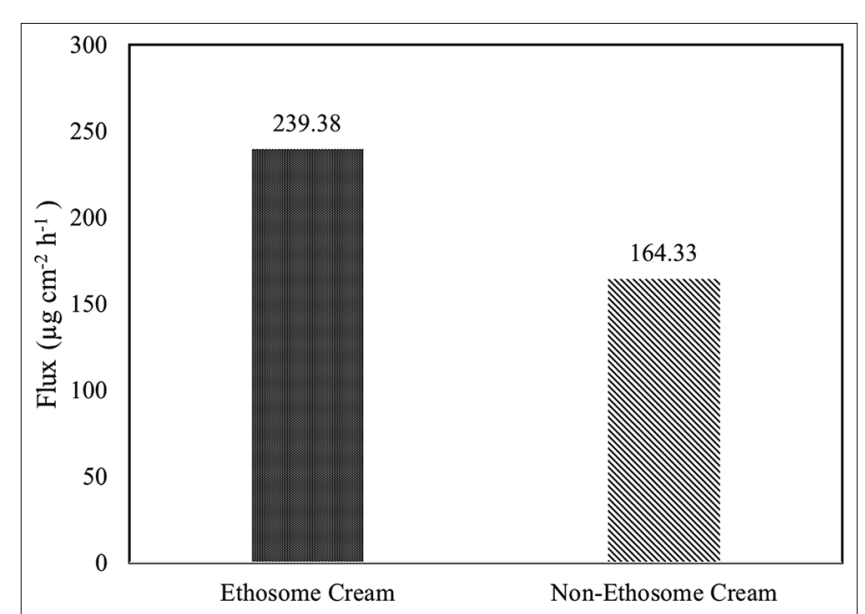

Fig. 5: Comparison of the flux rates of asiaticoside in the ethosomal and non-ethosomal creams

\section{CONCLUSION}

Our findings revealed that ethosomes can act as topical carriers for natural agents, such as asiaticoside. In addition, ethosomal cream can increase the stability and penetration ability in comparison to nonethosomal cream. Finally, the increased penetration of asiaticoside renders ethosome suitable as a carrier for pharmaceuticals and cosmetic applications of natural agents in the treatment of stretch marks, wound healing, and topical antimicrobials.

\section{ACKNOWLEDGMENT}

This study was financially supported by PITTA 2017 Universitas Indonesia.

\section{CONFLICTS OF INTEREST}

All authors have none to declare.

\section{REFERENCES}

1. Salter SA, Kimball AB. Striae gravidarum. Clin Dermatol 2006;24:97-100.
2. Ministry of Health Republic of Indonesia. Indonesian Materia Medics. $1^{\text {st }}$ ed. Jakarta: Ministry of Health Republic of Indonesia; 1977.

3. Lee JH, Kim HL, Lee MH, You KE, Kwon BJ, Seo HJ, et al. Asiaticoside enhances normal human skin cell migration, attachment and growth in vitro wound healing model. Phytomedicine 2012;19:1223-7.

4. Elsaie ML, Baumann LS, Elsaaiee LT. Striae distensae (stretch marks) and different modalities of therapy: An update. Dermatol Surg 2009;35:563-73.

5. Beltrami B, Vassallo C, Berardesca E, Borroni G. Anti-inflammatory, antimicrobial, comedolytic effects of a topical plant complex treatment in acne vulgaris: A clinical trial. J Appl Cosmetal 2001;10:11-20.

6. Zhang CZ, Niu J, Chong YS, Huang YF, Chu Y, Xie SY, et al. Porous microspheres as promising vehicles for the topical delivery of poorly soluble asiaticoside accelerate wound healing and inhibit scar formation in vitro and in vivo. Eur J Pharm Biopharm 2016;109:1-3.

7. Ajazuddin, Saraf S. Applications of novel drug delivery system for herbal formulations. Fitoterapia 2010;81:680-9.

8. Apriani EF, Nurleni N, Nugrahani HN, Iskandarsyah I. Stability testing of azelaic acid cream based ethosome. Asian J Pharm Clin Res 2018;11:270-3

9. Malvern Instruments. Zetasizer Nano Series User Manual. Ch. 4. Worcestershire: Malvern Instruments, Ltd.; 2013. p. 9.

10. Thakker DK, Chern WH. Development and validation of in vitro release tests for semisolid dosage forms-case study. Dissolution Technol 2003;10:10-5.

11. Anwar E, Utami TD, Ramadon D. Transfersomal gel containing green tea (Camellia sinensis L. Kuntze) leaves extract: Increasing in vitro penetration. Asian J Pharm Clin Res 2017;10:294-8.

12. Nurleni N, Iskandarsyah I, Aulia A. Formulation and penetration testing of ethosome azelaic acid on abdominal skin white male rats (Rattus norvegicus) with Franz diffusion cell. Asian J Pharm Clin Res 2018;11:327-30.

13. Laouini A, Jaafar MC, Limayem BI, Sfar S, Charcosset C, Fessi H. Preparation, characterization and applications of liposomes: State of the art. J Colloid Sci Biotechnol 2012;1:147-68.

14. D'Souza GG, editor. Liposomes Methods and Protocols. $2^{\text {nd }}$ ed. New York: Humana Press; 2017.

15. Liu Y, Wen C, Yang Y. Development of ethosome-like catanionic vesicles for dermal drug delivery. J Taiwan Inst Chem Eng 2012;43:830-8.

16. Rakesh R, Anoop KR. Ethosome for transdermal and topical drug delivery. Int J Pharm Pharm Sci 2012;4:17-24.

17. Wu X, Guy RH. Application of nanoparticles in topical drug delivery in cosmetics. J Drug Deliv Sci Technol 2009;19:371-84.

18. Ansel HC, Allen LV, Popovich NG, editors. Ansel's Pharmaceutical Dosage Forms and Drug Delivery Systems. $9^{\text {th }}$ ed. Philadelphia, PA: Wolters Kluwer; 2011. 